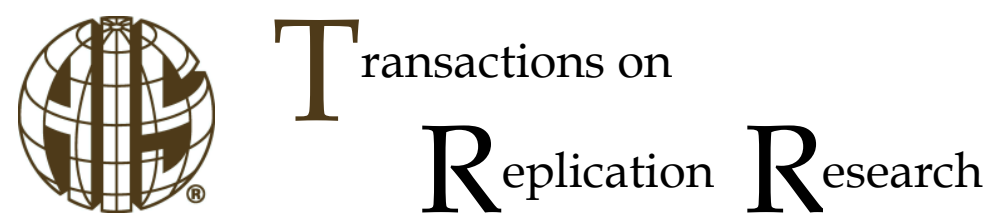

Conceptual Replication

ISSN 2473-3458

\title{
Cognitive Absorption: An Empirical Examination of 3-D Immersive Virtual World Users
}

\author{
Vishal Midha \\ Department of Accounting and Business Information Systems \\ Illinois State University, USA \\ vmidha@illinoisstate.edu
}

\begin{abstract}
:
The purpose of this conceptual replication study is to validate the cognitive absorption construct and the model proposed by Agarwal and Karahanna (2000) in the context of 3-D immersive virtual worlds. For this the original scale items were adapted to the new context, and the model was tested with the data collected from 307 customers of a large technology firm who voluntarily participated in a knowledge sharing activity in Second Life, a 3D virtual world platform. Overall, the replication results support the original model in the new setting - customers of a service firm involved in real life knowledge sharing activity in Second Life. Similar to the original study, this study finds that cognitive absorption positively influences perceived ease of use and perceived usefulness. In addition, unlike the original study, this replication study also finds support for positive relationship between perceived ease of use and perceived usefulness.
\end{abstract}

Keywords: Cognitive absorption, Virtual worlds, Second Life

The manuscript was received 08/07/2016 and was with the authors 4 months for 2 revisions.

\section{Introduction}

In providing an alternative perspective to the dominant cognitive drives of technology acceptance, Agarwal and Karahanna (2000) introduced the concept of cognitive absorption (CA) to explain why users behave in particular ways toward information technologies. They defined cognitive absorption as the state of deep involvement or the holistic experience that a user has with information technology such that the individual loses the notion of time and is so intensely involved in an activity that nothing else seems to matter. Further, using the traits of absorption (Tellegen and Atkinson 1974), state of flow (Csikszentmihalyi 1990), and notion of cognitive engagement (Webster and Ho 1997) as the roots, Agarwal and Karahanna also identified five dimensions of CA: temporal dissociation, focused immersion, heightened enjoyment, control, and curiosity. Table 1 summarizes the five dimensions that exhibit users' state of deep involvement (Agarwal and Karahanna, 2000):

\begin{tabular}{|l|l|}
\hline \multicolumn{2}{|c|}{ Table 1. Cognitive Absorption Dimensions } \\
\hline Dimension & Short Description \\
\hline TD & $\begin{array}{l}\text { Temporal dissociation refers to a user's inability to register the passage of time while engaged in an } \\
\text { interaction. This dissociation allows the user to perceive herself as having enough time to complete } \\
\text { the task at hand. }\end{array}$ \\
\hline $\mathrm{FI}$ & $\begin{array}{l}\text { Focused immersion is the experience of total engagement. When a user becomes immersed in an } \\
\text { activity, her level of cognitive burden associated with the activity is reduced. }\end{array}$ \\
\hline $\mathrm{HE}$ & $\begin{array}{l}\text { Heightened enjoyment captures the pleasurable aspects of an interaction. When a user experiences } \\
\text { pleasure in an activity, she views the activity as less taxing. }\end{array}$ \\
\hline $\mathrm{CO}$ & $\begin{array}{l}\text { Control refers to a user's perception of being in charge of the interaction. A sense of being in charge } \\
\text { and exercising control reduces the user's perceived difficulty in task performance. }\end{array}$ \\
\hline $\mathrm{CU}$ & $\begin{array}{l}\text { Curiosity is the extent the experience arouses an individual's sensory and cognitive curiosity. } \\
\text { Amplified curiosity invokes excitement about available possibilities, and that, in turn, reduces the } \\
\text { perceived cognitive burden associated with the experience. }\end{array}$ \\
\hline
\end{tabular}


Derived from the technology acceptance model, the effects of CA on behavioral intentions are mediated by perceived usefulness and perceived ease of use, whereby perceived ease of use has a positive influence on perceived usefulness. CA casts a positive influence on perceived ease of use because the intrinsically motivating state of CA "creates perceptions of a lower cognitive burned because the individual is experiencing pleasure from the activity and is willing to expend more effort on it" (Agarwal and Karahanna 2000). The positive influence of CA on perceived usefulness is justified through self-perception theory (Bem 1972) and cognitive dissonance theory (Festinger 1976). Individuals rationalize their actions and reduce cognitive dissonance, a psychological state that arises when an individual holds two inconsistent cognitive structures at the same time, by attributing instrumental value to it. While in the cognitive absorption state, the individual rationalizes "I am voluntarily spending a lot of time on this and enjoying it, therefore, it must be useful" (Agarwal and Karahanna 2000).

The model proposed by Agarwal and Karahanna (2000) has characterized the CA research in the information systems field until today. Though CA has helped us in explaining why users behave in particular ways toward information technologies, only few research studies have explicitly used the CA concept (Chandra et al, 2012). For example, Park et al (2008) proposed a conceptual model linking the use of environment induced affordances to enhance the flow state, which in turn increases customers' perceived brand equity. Saade and Bahli (2005) explored CA in the context of Internet-based learning systems used by higher educational institutions and showed that CA positively influences students' intentions to use learning systems, mediated through ease of use and perceived usefulness. Using responses from 172 subjects from Taiwan, Lin (2009) showed that CA significantly affects intentions to use 2D virtual communities, such as Yahoo! Group, for online social interactions. In contrast, Chandra et al (2012) applied the CA construct to workplace collaboration through virtual worlds. Using the data from 197 virtual world users from a Singapore university campus, they demonstrated CA and user trust to be the mechanisms leading to users' increased intentions towards using virtual worlds in workplace settings.

In this paper, we replicate the original CA study by Agarwal and Karahanna (2000) to assess its robustness and external validity in the context of 3-D immersive virtual worlds. While doing so, we also address several of the limitations listed in their original work and answer to their call for extending the generalizability of their model to different technologies (other than World Wide Web), to different subjects (beyond the educational setting subjects), and to different contexts (other than work environments). The current study conceptually replicates and tests the consequents of cognitive absorption portion of Agarwal and Karahanna's (2000) model by using data from customers of a IT service firm (a different set of subjects) in Second Life, a 3-D immersive virtual world (different technology). The subjects in the study were involved in real-life volitional knowledge seeking or knowledge sharing activity (different from work environment) in Second Life.

Most of the business tasks that can be conducted in the 2D environment can typically be conducted in 3D virtual worlds as well. However, 3D virtual worlds, such as Second Life, provide additional affordances and are objectively rich because of synchronous contact, strong visual stimuli, available social cues, and possible communication through multiple channels, including audio, visual, and text. Owing to the richness and immersive nature of Second Life platform, its users are expected to experience a significant degree of $\mathrm{CA}$. On the other hand, such kind of cognitive absorption is not necessarily associated with knowledge sharing or knowledge seeking activities. Hence, combining the two allows us to explore how different affordances and richness of 3D virtual worlds interact to create CA experience for users during knowledge seeking or knowledge sharing tasks.

Figure 1 and Table 2 present the model and list of hypotheses, respectively. 


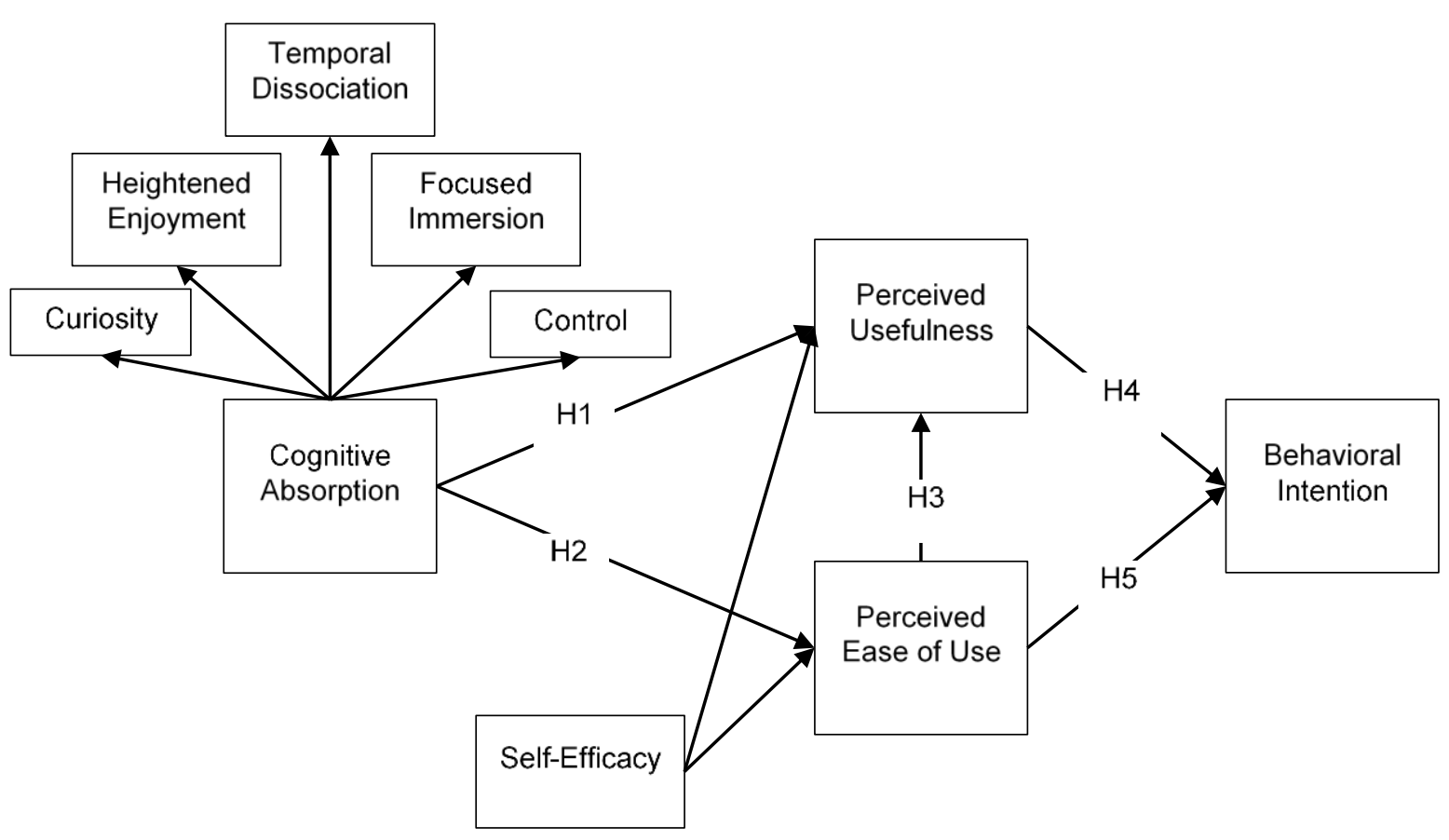

Figure 1. Research Model

Table 2. Hypotheses

$\mathrm{H} 1$ : After controlling for self-efficacy perceptions, cognitive absorption with the information technology (Second Life) has a positive effect on the perceived usefulness of the information technology (Second Life).

$\mathrm{H} 2$ : After controlling for self-efficacy perceptions, cognitive absorption with the information technology (Second Life) has a positive effect on the perceived ease of use of the information technology (Second Life).

H3: Perceived ease of use of the information technology (Second Life) has a positive effect on the perceived usefulness of the information technology (Second Life).

H4: Perceived usefulness of the information technology (Second Life) has a positive effect on behavioral intention to use the information technology (Second Life).

H5: Perceived ease of use of the information technology (Second Life) has a positive effect on behavioral intention to use the information technology (Second Life).

\section{Methods}

\section{Participants and Experimental Procedures}

Data were collected through a Web-based questionnaire survey. Participants in the study were customers of ServiceTech (a pseudonym). ServiceTech (ST) is a leading technology firm with its offices in three different continents and it provides technology product services and solutions to over 50,000 customers of numerous other firms spread across the globe. In addition to employing online chats, discussion forums, and knowledge bases to provide product- and service-support to the customers, ST also explored using Second Life, one of the most popular and successful 3-D immersive virtual worlds, for providing service to its customers. The current study employed ST's customers in Second Life to test the research model.

A total of 1,500 ST customers were requested to participate in Second Life platform where they could seek, or provide to others, products or services related information. There were 443 ST customers who participated in the study, but only 307 survey responses were complete and useful for analysis, yielding a $20.46 \%$ response rate. Table 3 provides the summary of participants' demographics. 


\section{Measures}

Measures for the five CA dimensions - temporal dissociation, focused immersion, heightened enjoyment, control, and curiosity- were adapted from Agarwal and Karahanna (2000). The perceived usefulness (PU), perceived ease of use (PEOU), as well as behavioral intention (BI) scales were adapted from Agarwal and Karahanna (2000). Self-efficacy was adapted from Wang and Haggerty (2011) and Agarwal and Karahanna (2000). All the adapted scales were adapted by changing item wording to focus on the context of Second Life. The complete list of items is provided in Table 5.

\begin{tabular}{|l|l|l|}
\hline \multicolumn{2}{|c|}{ Table 3. Descriptive Statistics of Participants (N=307) } \\
\hline Demographics & Male & Percentage \\
\hline \multirow{4}{*}{ Gender } & Female & $68.1 \%$ \\
\cline { 2 - 3 } & Undisclosed & $30.6 \%$ \\
\hline \multirow{5}{*}{ Age } & $18-25$ & $1.3 \%$ \\
\cline { 2 - 3 } & $26-35$ & $55.4 \%$ \\
\cline { 2 - 3 } & $36-55$ & $22.8 \%$ \\
\cline { 2 - 3 } & $>55$ & $18.9 \%$ \\
\hline Education & High School & $3.0 \%$ \\
\cline { 2 - 3 } & Some college & $39.1 \%$ \\
\cline { 2 - 3 } & Bachelors & $38.8 \%$ \\
\cline { 2 - 3 } & Graduate or higher & $17.6 \%$ \\
\hline
\end{tabular}

\section{Data Analysis}

\section{Analysis Technique}

Similar to Agarwal and Karahanna (2000), partial least squares (PLS), a component-based Structural Equation Modeling (SEM) technique, was used to validate the constructs' measures and test the research model and hypotheses. SEM is a statistical methodology that takes a confirmatory approach to the analysis of structured casual relationships. Partial Least Squares (PLS) was chosen because it uses a component based approach of estimation and places minimal restrictions on measurement scales, sample size, and residual distributions (Chin et al, 2003).

\section{Measurement Model Validation}

The results of psychometric properties are summarized in Table 4 and Table 5. Reported statistics include composite reliability, average variance extracted, square root of average variance extracted, inter-construct correlations, and factor loadings for the measurement model.

General rules have been provided by prior IS research to establish convergent validity and discriminant validity. Prior studies indicated that internal consistency for the constructs is further validated through composite reliability and Average Variance Extracted (AVE) (Fornell and Larcker, 1981). Typically, 0.70 is considered as the threshold of internal consistencies for all variables (Pavlou and Fygenson, 2006).

\begin{tabular}{|l|l|l|l|l|l|l|l|}
\hline \multicolumn{7}{|c|}{ Table 4. Inter-Construct Correlation Matrix and Average Variance Extracted } \\
\hline & TD & HE & CU & FI & CO & PU & PEOU \\
\hline TD & 0.63 & & & & & & \\
\hline HE & .39 & 0.70 & & & & & \\
\hline CU & .48 & .32 & 0.74 & & & & \\
\hline FI & .39 & .30 & .27 & 0.64 & & & \\
\hline CO & .31 & .46 & .24 & .16 & 0.85 & & \\
\hline PU & .35 & .36 & .34 & .35 & .35 & 0.77 & \\
\hline PEOU & .46 & .37 & .34 & .33 & .32 & .41 & 0.78 \\
\hline
\end{tabular}

Diagonal Elements (shaded) are the square root of the variance shared between the constructs and their measurement. TD: Temporal Dissociation (CA); HE: Heightened Enjoyment (CA); CU: Curiosity (CA); FI: Focused Immersion (CA); CO: Control (CA); PU: Perceived Usefulness; PEOU: Perceived Ease of Use 
To assess discriminant validity, the square root of each construct's average variance extracted (AVE) should be larger than the correlations between constructs, i.e., the off-diagonal elements in Table 4 (Fornell and Larcker 1981). All constructs meet this requirement. Similar to Cronbach's alpha, composite reliability is a measure of internal consistency. Unlike Cronbach's alpha, the composite reliability takes into account the actual loadings used to construct factor scores, and thus is a better measure of internal consistency. All composite reliability values are greater than 0.88 , indicating good internal consistency. With the exception of two items for the control variable - self efficacy, all other factor loadings were greater than 0.7 . Due to the poor loadings, two of those items were dropped from further analysis.

\begin{tabular}{|c|c|c|}
\hline \multicolumn{3}{|c|}{ Table 5. Measurement Model Statistics } \\
\hline Construct & Indicator & $\begin{array}{l}\text { Factor } \\
\text { Loadings }\end{array}$ \\
\hline \multirow{5}{*}{$\begin{array}{l}\text { Temporal } \\
\text { Dissociation } \\
A L=0.85 \\
C R=0.89 \\
\text { AVE }=0.63\end{array}$} & Time appeared to go by very quickly when I was using Second Life. & 0.781 \\
\hline & Sometimes I lost track of time when I was using Second Life. & 0.803 \\
\hline & Time flew when I was using Second Life. & 0.775 \\
\hline & $\begin{array}{l}\text { Most times when I got on to Second Life, I ended up spending more time } \\
\text { than I had planned. }\end{array}$ & 0.743 \\
\hline & I often spent more time in Second Life than I had intended. & 0.869 \\
\hline \multirow{4}{*}{$\begin{array}{l}\text { Heightened } \\
\text { Enjoyment } \\
A L=0.85 \\
C R=0.90 \\
A V E=0.70\end{array}$} & I had fun in Second Life. & 0.758 \\
\hline & Using Second Life provided me with a lot of enjoyment. & 0.861 \\
\hline & I enjoyed using Second Life. & 0.822 \\
\hline & Using Second Life bored me * & 0.897 \\
\hline \multirow{3}{*}{$\begin{array}{l}\text { Curiosity } \\
A L=0.83 \\
C R=0.90 \\
A V E=0.74\end{array}$} & Using Second Life excited my curiosity. & 0.879 \\
\hline & Interacting in Second Life made me curious. & 0.810 \\
\hline & Using Second life aroused my imagination. & 0.890 \\
\hline \multirow{5}{*}{$\begin{array}{l}\text { Focused Immersion } \\
A L=0.86 \\
C R=0.90 \\
A V E=0.64\end{array}$} & While using Second Life, I was able to block out most other distractions. & 0.786 \\
\hline & While using Second Life, I was absorbed in what I was doing. & 0.822 \\
\hline & While using Second Life, I was immersed in the task I was performing. & 0.758 \\
\hline & $\begin{array}{l}\text { When using Second Life, I got distracted by other attentions very easily. } \\
*\end{array}$ & 0.827 \\
\hline & While using Second Life, my attention did not get diverted very easily. & 0.813 \\
\hline \multirow{3}{*}{$\begin{array}{l}\text { Control } \\
A L=0.91 \\
C R=0.94 \\
\text { AVE }=0.85\end{array}$} & When using Second life I felt in control & 0.894 \\
\hline & I felt that I had control over my interaction in Second Life. & 0.934 \\
\hline & Second Life allowed me to control my interactions. & 0.937 \\
\hline \multirow{4}{*}{$\begin{array}{l}\text { Perceived } \\
\text { Usefulness } \\
\text { AL }=0.90 \\
\text { CR }=0.93 \\
\text { AVE }=0.77\end{array}$} & I found Second Life useful in obtaining product or service information. & 0.906 \\
\hline & Using Second Life enhanced my productivity. & 0.914 \\
\hline & $\begin{array}{l}\text { Using Second Life enhanced my effectiveness in finding product or } \\
\text { service information. }\end{array}$ & 0.867 \\
\hline & Using Second Life made it easier to find product or service information. & 0.833 \\
\hline \multirow{4}{*}{$\begin{array}{l}\text { Perceived Ease of } \\
\text { Use } \\
A L=0.90 \\
C R=0.93 \\
A V E=0.78\end{array}$} & Learning to use Second Life was easy for me & 0.872 \\
\hline & I found it easy to get the Web to do what I wanted it to do. & 0.877 \\
\hline & It was easy for me to become skillful at using Second Life. & 0.902 \\
\hline & I found Second Life easy to use. & 0.870 \\
\hline \multirow{3}{*}{$\begin{array}{l}\text { Behavioral Intention } \\
A L=0.80 \\
C R=0.88 \\
A V E=0.71\end{array}$} & I plan to use Second Life in the future. & 0.838 \\
\hline & I intend to continue using Second Life in the future. & 0.844 \\
\hline & I expect my use of Second Life to continue in the future. & 0.848 \\
\hline \multirow{6}{*}{$\begin{array}{l}\text { Efficacy } \\
A L=0.71 \\
C R=0.89 \\
A V E=0.72\end{array}$} & I could find product or services information using Second Life if & \\
\hline & I had never used one like this before. & 0.825 \\
\hline & There is no one around to tell me what to do as I go. & 0.861 \\
\hline & I had only the manuals for reference. & Dropped \\
\hline & I could call someone for help if I got stuck. & 0.876 \\
\hline & I had seen someone else using it before trying it myself. & Dropped \\
\hline
\end{tabular}


A concern with self-reported data is the possible presence of a systematic error. To reduce the effects of social desirability or self-presentation, the participants were assured of the confidentiality and anonymity of their responses. In order to assess whether common method bias was a concern, the Harmon one-factor test was conducted by entering all independent and dependent variables in an exploratory factor analysis (Podsakoff and Organ 1986). Harman's test showed that the first factor accounted for $29.62 \%$ of the total variance, which is less than 50 percent of the total variance, indicating a lack of a substantial common methods bias. We also followed Liang et al. (2007) and included in the PLS model a common method factor whose indicators included all the principal constructs' indicators and calculated each indicator's variance substantively explained by the principal construct and by the method. The results show that the average substantively explained variance of the indicators is 0.72 , while the average method based variance is 0.0054. Given the small magnitude of method variance, it was concluded that the common method is unlikely to be a serious concern for this study.

\section{Testing the Structural Model}

SmartPLS 2.0 (Ringle et al, 2005) was used to test the structural model. Bootstrapping was performed to test the statistical significance of path coefficients. The PLS path coefficients are shown in Figure 2. Item loadings of each construct are omitted for structural model.

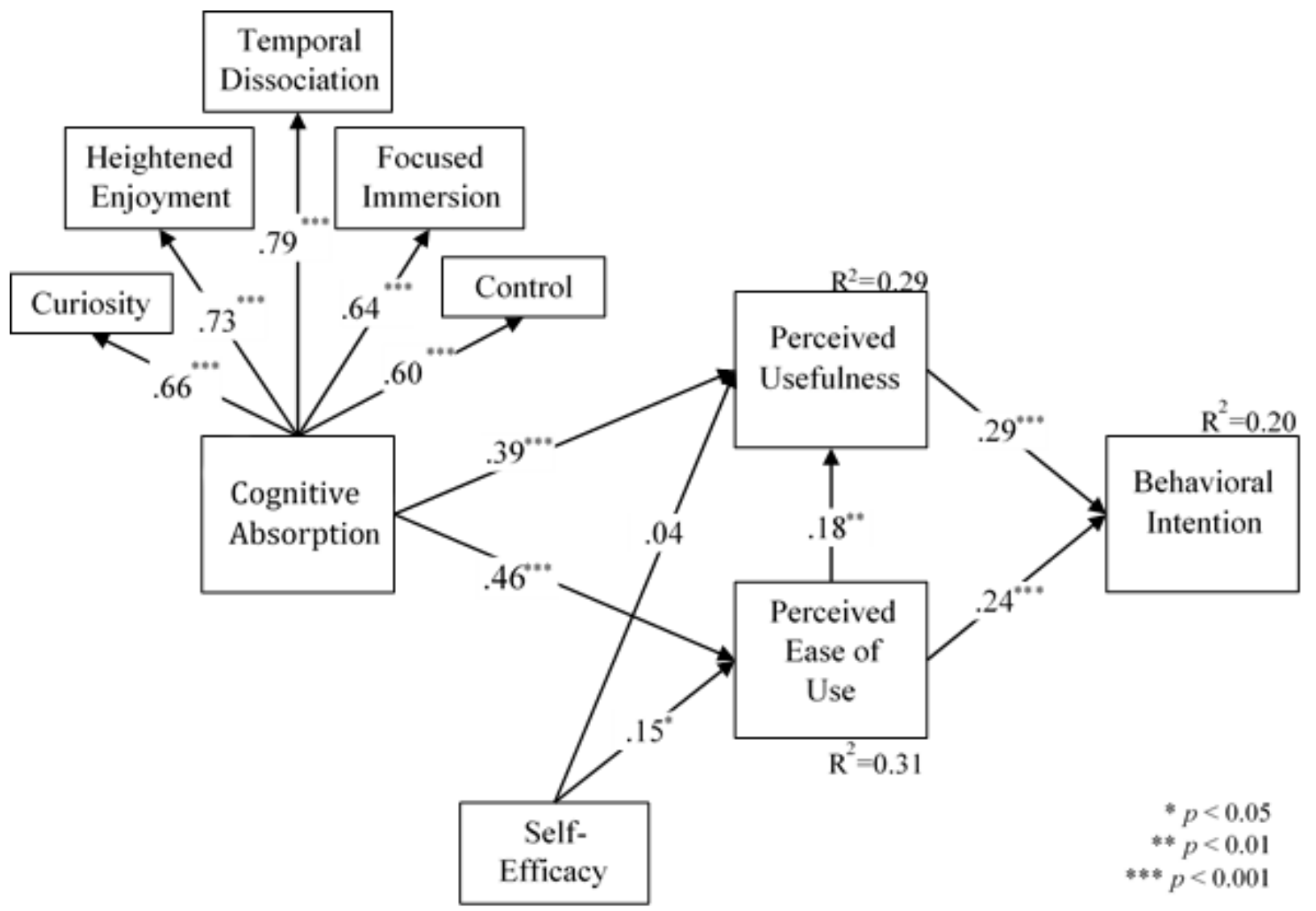

Figure 2. PLS Results for the Research Model

All the path coefficients for the hypothesized relationships are as proposed and significant. Figure 2 depicts the main path coefficients, p-values, and explained endogenous variables' variances (R2) for the structural model. As can be seen from Figure 2, all hypothesized paths in the research model are supported. As expected, CA was significantly associated with both PU (path coefficient $=0.39, p<0.001$ ) and PEOU (path 
coefficient $=0.46, \mathrm{p}<0.001$ ), supporting $\mathrm{H} 1$ as well as $\mathrm{H} 2$. $\mathrm{PU}$ was also found to be positively associated with PEOU (path coefficient $=0.18, p<0.01$ ), supporting $\mathrm{H} 3$. Finally, $\mathrm{PU}$ and PEOU were found to be positively associated with $\mathrm{BI}$ (path coefficients $=0.29, \mathrm{p}<0.001$ and $=0.24, p<0.01$ respectively), confirming $\mathrm{H} 4$ and H5. Similar to Agarwal and Karahanna (2000), a post-hoc direct effect of CA on BI was also tested and found to be significant. However, the discussion of the CA-BI relationship is limited in this paper as it was neither the focus of and nor theorized in the original study.

Overall, approximately $29 \%$ of the variance in PU, $31 \%$ of the variance in PEOU, $20 \%$ of the variance in $\mathrm{BI}$ was explained by the antecedent variables. The tabulated results of the structural model for the current study and Agarwal and Karahanna (2000) are presented in Table 6.

\begin{tabular}{|c|c|c|c|c|}
\hline \multicolumn{5}{|c|}{ Table 6. Structural Model Results } \\
\hline \multirow[t]{2}{*}{ Hypothesis } & \multicolumn{2}{|c|}{ Present Study } & \multicolumn{2}{|c|}{ Agarwal \& Karahanna (2000) } \\
\hline & Coefficient & Support & Coefficient & Support \\
\hline $\mathrm{H} 1: \mathrm{CA} \rightarrow \mathrm{PU}$ & $0.39^{\star \star \star}$ & Yes & $0.52^{\star \star \star}$ & Yes \\
\hline $\mathrm{H} 2: \mathrm{CA} \rightarrow \mathrm{PEOU}$ & $0.46^{\star * \star}$ & Yes & $0.59^{\star \star \star}$ & Yes \\
\hline $\mathrm{H} 3: \mathrm{EOU} \rightarrow \mathrm{PU}$ & $0.18^{\star *}$ & Yes & 0.196 & No \\
\hline $\mathrm{H} 4: \mathrm{PU} \rightarrow \mathrm{BI}$ & $0.29^{\star \star \star}$ & Yes & $0.48^{\star \star \star}$ & Yes \\
\hline $\mathrm{H} 5: \mathrm{EOU} \rightarrow \mathrm{BI}$ & $0.24^{\star \star \star}$ & Yes & $0.31^{* \star *}$ & Yes \\
\hline
\end{tabular}

\section{Discussion}

The purpose of this study was to conceptually replicate the cognitive absorption construct and the model proposed by Agarwal and Karahanna (2000) in the context of 3-D immersive virtual worlds. Extending the replication of an existing instrument is an approach that has been advocated by various researchers (Berthon et al., 2002; Boudreau et al., 2001). This study assesses the robustness and external validity of the Agarwal and Karahanna CA model in 3-D context.

Overall, based on the findings of this study, the notion advanced by Agarwal and Karahanna (2000) was supported in the 3-D context. In addition, this study addresses some of the limitations of the original study and extends the generalizability of the original model. By replicating the study with real-world users engaged in knowledge seeking or knowledge sharing volitional tasks in 3-D immersive virtual worlds, the current study extends the generalizability of the original study to (i) a new technology, (ii) a new usage context, and (iii) a different set of users. With the average age of 28 years of the subjects, the current study also addresses Agarwal and Karahanna's (2000) call to establish the generalizability of the findings to age groups other than the respondents of their study (which was 23 years).

Similar to Agarwal and Karahanna (2000), cognitive absorption was measured as a superordinate secondorder construct reflected in five dimensions - temporal dissociation, focused immersion, heightened enjoyment, control, and curiosity. Doing so allowed to theorize about and evaluate the influence of the second-order construct, rather than the influence of its five dimensions, PEOU, and PU. Due to the limitations imposed by the analytical tools available at the time of the original study, Agarwal and Karahanna (2000) represented the CA dimensions by factor scores derived from the confirmatory factor analysis. Owing to the advancements in analytical tools, the current study was able to model all the constructs, including the CA dimensions, as reflective with multiple indicators.

Though many of the limitations of the original study were addressed, the current study is not without its own limitations. The results of this study discussed next have to be interpreted in light of these limitations. One of the limitations of this replication study is that it uses a trimmed version of self-efficacy scale to minimize respondent fatigue (Wang and Haggerty, 2011). Though the trimmed version was approved by one of the authors of the original scale (Wang and Haggerty, 2011), it is possible that this change may have resulted in the non-significant effect of self-efficacy on perceived usefulness. Another limitation is that it is a crosssectional study. Although cross-sectional designs often benefit from high construct validity, findings from this study are limited with respect to inferences that can be drawn (Judd \& Kenny, 1981). A longitudinal study with subjects' perceptions and intentions over time is likely to generate more insightful findings. Lastly, though our statistical analyses based on Podsakoff and Organ (1986) and Liang et al (2007) show a lack of significant common method bias in our data sample, the concerns raised by a later study (Chin et al, 2012) reveal the possibility that the common method bias may not have been correctly ruled out. Consequently, the results should be interpreted in the light of potential common method bias. 
The study by Agarwal and Karahanna (2000) focused on World Wide Web (www) in general. At the time of testing of the original model by Agarwal and Karahanna, the World Wide Web could primarily be considered as 2-D environments, in which the individuals interacted with technology by themselves. On the other hand, in the 3-D immersive virtual worlds, the individuals not only interact with the technology, they also interact with other virtual world users. As a result, the immersive virtual worlds provides for interaction between the platform's technical environment and the users' social environment. Clearly, the 3-D immersive virtual worlds provide affordances that can offer a different level of CA experience to its users. This experience is further enhanced by the visual and aural cues that the 3-D immersive worlds offer.

Even the situational context used in the current study lends to a higher level of cognitive absorption. Agarwal and Karahanna (2000) study alludes to work environment in which a greater value is placed on extrinsic rather than intrinsic motivators. On the other hand, the current study deals with personal and volitional knowledge seeking settings in which the internal motivators might be more prevalent. When people are intrinsically motivated, they are more likely to experience interest and enjoyment, feel competent and selfdetermining, and accordingly experience higher levels of total involvement (Shang et al, 2005).

Agarwal and Karahanna (2000) did not find support for the relationship between PEOU and PU. However, this study found a significant relationship between PEOU and PU. The relationship is based on the notion that to the extent the lower cognitive burden imposed by a system frees up attentional resources to focus on other matters, it helps to reveal the usefulness of the system to users. One possible reason for the differing results for this relationship is the study subjects' experience with the platforms employed in the two studies. The subjects in Agarwal and Karahanna (2000) were experienced web users and the subjects in the current study were new users of 3-D immersive virtual worlds. The finding is consistent with works that show that the relationship between PEOU and PU weakens as the system users gain experience with the system (Hess et al 2014; Karahanna et al. 1999). Another possibility for this differing result could be that the subjects in two studies have considerable differences in general competence and adaptability to new technologies. The majority of the subjects employed in the current study belongs to the millennial generation, which is generally considered to be confident with existing and adapting to new technology (Schooley 2008). So, the increased PEOU of the 3-D platform might have allowed the subjects to focus more on its usefulness. The millennial generation is also more likely to explore diverse features offered by technologies (Chung et al, 2010), thus increasing the likelihood of perceiving higher usefulness of technology. 


\section{References}

Agarwal, R., \& Karahanna, E. (2000). Time flies when you're having fun: Cognitive absorption and beliefs about information technology usage, MIS Quarterly 24(4), 665-694.

Bern, D.J. (1972). Self-perception theory. In L. Berkowitz (Ed.), Advances in experimental social psychology (Vol. 6). New York: Academic Press.

Berthon, P., Pitt, L., Ewing, M., \& Carr, C. L. (2002). Potential research space in MIS: A framework for envisioning and evaluating research replication, extension, and generation. Information Systems Research, 13(4), 416-427.

Boudreau, M.C., Gefen, D., \& Straub, D. W. (2001). Validation in information systems research: A state-ofthe-art assessment. MIS Quarterly, 25(1), 1-24.

Byrne. BM. (1998). Structural equation modeling with LISREL, PRELIS, and SIMPLIS: basic concepts, applications, and programming. Mahwah XJ: Lawrence Erlbaum Associates.

Chandra, S., Srivastava, S.C., \& Theng, Y-L. (2012). Cognitive absorption and trust for workplace collaboration in virtual worlds: An information processing decision making perspective. Journal of the Association for Information Systems 13(10), Article 3.

Chin. W.W., Marcolin. B., \& Xewsted, P. (2003). A partial least squares latent variable modeling approach for measuring interaction effects: Results from a Monte Carlo simulation study and an electronic mail adoption study. Information Systems Research, 14(2), 139-217.

Chin, W., Thatcher, J.B., Wright, R.T. (2012). Assessing common method bias: problems with the ULMC technique. MIS Quarterly, 36(3), 1003-1019

Chung JE, Park N, Wang H, Fulk J, \& Mclaughlin M. (2010). Age differences in perceptions of online community participation among non-users: An extension of the Technology Acceptance Model. Computers in Human Behavior, 26(6), 1674-1684

Csikszentmihalyi, M. (1990). Flow: The psychology of optimal experience. NY: Harper \& Row.

Festinger, L. (1976). A theory of cognitive dissonance. Stanford, CA: Stanford University Press.

Fornell. C. \& Larcker. Y.F. (1981) Equating structural equation models with unobservable variables and measurement error. Journal of Marketing Research, 15(1), 39-50.

Hess, T. J., McNab, A. L., \& Basoglu, K. A. (2014). Reliability generalization of perceived ease of use, perceived usefulness, and behavioral intentions. MIS Quarterly, 38(1), 1-A29.

Judd, C., \& Kenny, D. (1981). Estimating the effects of social interventions. UK: Cambridge University Press.

Karahanna, E., Straub, D. W., and Chervany, N. L. 1999. "Information technology adoption across time: A cross-sectional comparison of pre-adoption and post-adoption beliefs," MIS Quarterly, 23(2), 183213

Liang, H., Saraf, N., Hu, Q., \& Xue, Y. (2007). "Assimilation of enterprise systems: The effect of institutional pressures and the mediating role of top management". MIS Quarterly, 31(1), 59-87.

Lin, H. (2009). "Examination of cognitive absorption influencing the intention to use a virtual community". Behaviour and Information Technology, 28(5), 421-431.

Park, S. A., Nah, F. F., DeWester, D., \& Eschenbrenner, B. (2008). "Virtual world affordances: Enhancing brand value". Journal of Virtual Worlds Research, 1(2), 1-18.

Pavlou, P.A., \& Fygenson M. (2006). Understanding \& predicting electronic commerce adoption: An extension of the theory of planned behavior. MIS Quarterly, 30(1), 115-143.

Podsakoff, P., and Organ, D. (1986). "Self-reports in organizational research: Problems and prospects," Journal of Management, 12(4), 531-544.

Ringle, Christian M., Wende, Sven, and Will, Alexander (2005). SmartPLS 2.0.M3. Hamburg: SmartPLS, http://www.smartpls.de. 
Saade, R., \& Bahli, B. (2005). "The impact of cognitive absorption on perceived usefulness and perceived ease of use in on-line learning: An extension of the technology acceptance model". Information and Management, 42(2), 317-327.

Schooley, C. (2008). Generational workforce strategies: Suggestions for coping. Research report, Forrester Research, Cambridge, MA.

Shang, R., Chen, Y., Shen, L. (2005). Extrinsic versus intrinsic motivations for consumers to shop on-line, Information \& Management 42, pp. 401-413.

Tellegen, A., Atkinson, G. (1974). Openness to absorbing and self-altering experiences ("absorption"), a trait related to hypnotic susceptibility. Journal of Abnormal Psychology, 83, pp. 268-277.

Wang, Y., and Haggerty, N. (2011) Individual virtual competence and its influence on work outcomes. Journal of Management Information Systems, 27(4), pp. 299-334

Webster, J., Ho, H. (1997): Audience engagement in multi-media presentations. The DATABASE for the Advances in Information Systems, 28, pp. 63-77. 


\begin{abstract}
About the Authors
Vishal Midha is an Associate Professor in the Department of Accounting at Illinois State University. His current research interests include OSS development, privacy and security concerns, and individual and organizational level adoption. He has published in journals such as Information Systems Research, Decision Support Systems, E-Markets, and Communications of the AIS.
\end{abstract}

Copyright ( 2016 by the Association for Information Systems. Permission to make digital or hard copies of all or part of this work for personal or classroom use is granted without fee provided that copies are not made or distributed for profit or commercial advantage and that copies bear this notice and full citation on the first page. Copyright for components of this work owned by others than the Association for Information Systems must be honored. Abstracting with credit is permitted. To copy otherwise, to republish, to post on servers, or to redistribute to lists requires prior specific permission and/or fee. Request permission to publish from: AIS Administrative Office, P.O. Box 2712 Atlanta, GA, 30301-2712 Attn: Reprints or via e-mail from ais@aisnet.org. 